\title{
Analisis Teknis dan Ekonomis Pengembangan Industri Rumah Apung Sebagai Pendukung Wisata Bahari Indonesia
}

\author{
Dido Cahya Mahardika P. dan Triwilaswandio WP. \\ Departemen Teknik Perkapalan, Fakultas Teknologi Kelautan, Institut Teknologi Sepuluh Nopember (ITS) \\ e-mail: triwilas@na.its.ac.id
}

\begin{abstract}
Abstrak-Tujuan dari studi ini adalah melakukan analisis teknis dan ekonomis pengembangan industri rumah apung di Indonesia. Pertama, melakukan analisis market pasar rumah apung terhadap lokasi - lokasi pariwisata bahari Indonesia yang dijadikan sebagai target pasar dari rumah apung. Kedua, melakukan perencanaan desain rumah apung termasuk pemilihan material dan konstruksi. Ketiga, melakukan perencanaan pembangunan pabrik termasuk pemilihan lokasi pabrik, proses produksi, penentuan kapasitas produksi, peralatan dan mesin yang digunakan dalam proses produksi. Lokasi pabrik berada di Jalan Raya Manyar, Manyar, Kab. Gresik, Jawa Timur. Terakhir, melakukan analisis ekonomis meliputi analisis biaya investai pembangunan industri yaitu sebesar $R$ p 5.715.716.000 berupa biaya pembelian tanah, pembangunan, pembelian peralatan dan mesin. hasil yang didapatkan adalah Payback Period terjadi pada tahun ke- 9 dengan nilai kira-kira sebesar Rp 1.571.240.000. Nilai Net Present Value kira-kira sebesar Rp 1.071.682.000. Nilai Internal Rate of Return sebesar 12,32\% lebih besar dari bunga bank yang telah ditetapkan yaitu $10,25 \%$.
\end{abstract}

Kata Kunci-Industri pendukung wisata bahari, Rumah apung, Kelayakan Investasi, Floating structures.

\section{PENDAHULUAN}

$\mathrm{S}_{\mathrm{d}}^{\mathrm{A}}$ ALAH satu upaya pengembangan industri pariwisata dapat dilakukan dengan cara pengembangan atraksi wisata bahari di Indonesiia sebagai daya tarik wisata. Pengembangan atraksi wisata ini tentunya direncanakan dan dilakukan sesuai dengan potensi dan kemampuan daerah untuk menyusun rencana dan mengelola secara optimal sesuai dengan sumber daya yang dimiliki. Suatu tempat atau kawasan wisata di suatu daerah baiknya memiliki beraneka warna ragam atraksi, baik itu merupakan atraksi keindahan alam, keagungan manifestasi kebudayaan, pusat perekonomian, maupun atraksi lengkap yang dalam keseluruhannya merupakan daya tarik kuat bagi para wisatawan, dalam maupun luar negeri. Salah satu Industri penunjang dan pendukung adalah pengembangan yang bergerak dibidang pariwisata bahari seperti industri wahana bahari, floating house, dermaga dll. Sebagai negeri yang memiliki potensi pariwisata bahari yang kaya, Indonesia masih belum banyak pemain yang bergerak dibidang industri pembangunan Rumah Apung yang dapat meningkatkann atraksi wisata bahari dan mampu menarik wisatawan lokal maupun mancanegara.
Dengan adanya Industri Rumah Apung diharapkan Indonesia mampu meningkatkan potensi wisata bahari yang tersebar di penjuru negeri dan dapat menjadi role model (sebagai acuan) desain industri Rumah Apung di Indonesia.

\section{TINJAUAN PUSTAKA}

\section{A. Tinjauan Rumah Apung}

Rumah apung, merupakan konsep rumah tinggal atau bersinggah dengan menggunakan media struktur apung. Konsep struktur terapung atau yang sering disebut 'Floating Structure' yang digunakan sebagai pengganti tanah dalam pembangunan sebuah bangunan. selain menjadi alternatif prearrangement wilayah disamping reklamasi, karena strukturnya mampu mengapung diatas air [1].

Dalam konsep struktur terapung ini, secara umum terdapat perbedaan yang sangat mendasar dibandingkan proses pembangunan struktur bangunan di darat.Struktur bangunan darat, proses pembangunannya sejak tahap awal hingga akhir dlakukan di tempat yang sama. Sebaliknya, struktur terapung, apapun jenisnya dibangun atau difabrikasi di tempat yang berbeda dengan di tempat instalasinya (knock-down). Perbedaan kondisi inilah yang menyebabkan perbedaan proses pembangunan dan teknologi yang diperlukan dalam aplikasinya.

Ada dua tipe dari struktur terapung, yaitu tipe semisubmersible dan pontoon.

a. Tipe semisubmersible, adalah membangun struktur terapung dia atas permukaan air laut dengan menggunakan column tubes atau elemen struktur ballast untuk meminimalkan efek gelombang dan menjadikannya agar tetap terapung. Tipe struktur ini dapat diaplikasikan pada anjungan lepas pantai, sepeti semisubmersible dan tension leg platforms.

b. Tipe pontoon merupakan struktur terapung yang sering ditemui pada beberapa pelabuhan biasanya ditempatkan pada wilayah yang mempunyai perairan cukup tenang, seperti teluk. Dari sisi konstruksi, aplikasi struktur terapung jauh lebih efisien karena tidak perlu pembuatan dan pengerjaan deasin pondai konvensional seperti tiang pancang dan sejenisnya. Konstruksi mengapung ini hanya diikat dengan mooring system dengan seabed. 
Dewasa ini dan di masa depan, diperkirakan struktur bangunan terapung akan menjadi primadona konstruksi.. Keuntungannya adalah tidak menimbulkan scouring pada pondasi pilar sebagai penumpu bangunan. Pilar konvensional umumnya mengalami masalah scouring atau gerusan yang dapat membahayakan pondasi struktur. Keuntungan dari penggunaan floating structure [2] adalah sebagai berikut:

a. Efisiensi konstruksi karena tidak perlu pembuatan dan pengerjaan desain pondasi

b. ramah lingkungan karena tidak merusak dan tidak menambah volume benda yang bersifat massive structure.

c. mudah dan cepat dalam pengerjaan karena proses pengerjaan dengan metode perakitan (assembling method).

d. tahan terhadap gempa karena secara struktur tidak tertanam di tanah atau tidak berbasis pondasi namun mengapung dan hanya di ikat dengan mooring.

e. mudah dipindah maupun diperbaiki karena sifatnya yang dapat dirakit (assembling method).

f. konstruksi apung tidak mengalami proses konsolidasi maupun setlemen.

g. cocok untuk pembuatan konstruksi yang mengedepankan estetika model atau bentuk dibandingkan metode konvensional .

\section{B. Biaya Produksi}

Dalam suatu biaya diketahui ada 2 istilah atau terminologi biaya yang perlu mendapat perhatian, yaitu:

a. Biaya (cost) yang dimaksud dengan pengertian biaya adalah semua pengorbanan yang dibutuhkan dalam rangka mencapai suatu tujuan yang diukur dengan nilai uang

b. Pengeluaran (expence) yang dimaksud dengan expence ini biasanya berkaitan dengan sejumlah uang yang dikeluarkan atau dibayarkan dalam rangka mendapatkan suatu hasil yang diharapkan Dalam kedua pengertian diatas dapat disimpulkan bahwa biaya (cost) memiliki pengertian yang jauh lebih lengkap dan mendalam dari pengeluaran.

Konsep dan istilah berkembang selaras dengan kebutuhan disiplin keilmuan dan profesi (ekonom, insinyur, akuntan, dan desainer) sehingga dalam pengklarifikasian biaya banyak pendekatan yang dapat detemui. Oleh karena itu klasifikasi biaya dapat terbagi menjadi:

a. Biaya berdasarkan waktu

Biaya berdasarkan waktu, meliputi:

1. Biaya masa lalu (hystorical cost), yaitu biaya yang secara rill telah dikeluarkan dan dapat dibuktikan dengan catatan historis pengeluaran keggiatan

2. Biaya perkiraan (predictive cost), yaitu perkiraan biaya yang akan dikeluarkan bila kegiatan itu dilaksanakan

3. Biaya actual (actual cost), yaitu biaya yang dikeluarkan sebenarnya diwaktu sekarang

b. Biaya berdasarkan kelompok sifat penggunaannya

Biaya berdasarkan kelompok sifat penggunaannya, meliputi:

1. Biaya investasi (investment cost), yaitu biaya yang ditanamkan dalam rangka mempersiapkan kebutuhan usaha untuk siap beroperasi dengan baik.
2. Biaya operasional (operational cost), yaitu biaya yang dikeluarkan saat menjalankan aktivitas usaha. Biaya operasional bersifat periodik dan dikeluarkan secara rutin selama usaha itu masih berjalan.

3. Biaya perawatan (maintenance cost), yaitu biaya yang dikeluarkan untuk merawat,menjaga, menjamin performa kerja suatu fasilitas dan peralatan usaha agar selalu baik dan siap digunakan.

c. Biaya berdasarkan produknya

Biaya berdasarkan produknya, meliputi:

1. Biaya Fabrikasi (faktory cost), yaitu biaya-biaya yang dikeluarkan pada saat proses produksi. Biaya fabrikasi terbagi menjadi 3 unsur, yaitu biaya langsung, biaya tenaga kerja langsung, dan biaya overhead.

2. Biaya komersial (commercial cost), yaitu akumulasi biaya yang dibutuhkan untukmembuat produk dapat dijual diluar biaya produksi dan dipergunakan untuk perhitungan harga jual produk. Biaya komersial terdiri dari biaya umum, biaya pemasaran, dan pajak usaha.

d. Biaya berdasarkan volume produk

Biaya berdasarkan volume produk, meliputi:

1. Biaya tetap (fixed cost), biaya yang dikeluarkan relatif sama walaupun volume produksinya berubah dalam batas tertentu

2. Biaya variable (variable cost), biaya yang berubah besarnya secara proposional dengan jumlah produk yang dibuat

3. Biaya semi variable (semi variable cost), biaya yang berubah tidak proposional dengan perubahan volume

\section{METODOLOGI PENEILITIAN}

\section{A. Jenis Metodologi Penelitian}

Metode Penelitian yang digunakan adalah metode deskriptif kualitatif, yaitu metode yang bersifat deskriptif di mana data yang didapat merupakan hasil wawancara, observasi, dan studi pustaka. Tujuan dari penelitian deskriptif ini adalah memberikan deskripsi, gambaran atau lukisan secara sistematis, faktual dan akurat mengenai fakta-fakta, sifat-sifat serta hubungan antar fenomena yang diselidik [3]

\section{B. Jenis dan Sumber Data}

a. Jenis Data

Jenis data yang digunakan dalam penelitian ini :

1. Data Kualitatif yaitu data yang didapat dari hasil wawancara dan observasi langsung dengan pihak terkait (Industri manufaktur rumah kayu dan floating structure). Selain itu data kualitatif dapat diperoleh melalui gambar hasil pemotretan dan rekaman video.

2. Data kuantitatif yaitu data yang berbentuk angka atau bilangan yang sesuai dengan kebutuhan penelitian.

b. Sumber Data

Berdasarkan sumbernya, data yang digunakan adalah :

1. Data primer merupakan data yang diperoleh atau dikumpulkan secara langsung dari sumber datanya. Teknik yang digunakan peneliti untuk mengumpulkan 
data primer antara lain wawancara dan observasi dengan pemilik serta pekerja dari industri manufaktur bangunan lepas pantai.

2. Data sekunder merupakan data yang diperoleh dari studi pustaka yang berkaitan dengan permasalahan yang dibahas oleh peneliti.

\section{Teknik Pengumpulan Data}

Pada tahap ini akan dilakukan pengumpulan data yang dilakukan dengan cara seperti di bawah ini :
a. Studi Pustaka
b. Survey Pendahuluan
c. Survey Lapangan

\section{Analisis Data}

Analisis yang diperlukan dalam penyelesaian studi ini adalah menggunakan analisis teknis dan ekonomis. Analisis teknis yang dilakukan meliputi pemilihan lokasi pembangunan industri manufaktur rumah apung, penentuan jumlah kebutuhan fasilitas produksi, perencanaan jumlah tenaga kerja yang dibutuhkan baik tenaga kerja langsung maupun tenaga kerja tak langsung, perencanaan struktur organisasi perusahaan sera perencanaan luas area dan desain layout pabrik yang sesuai.

\section{KONDISI EKSISTING RUMAH APUNG DAN ANALISIS MARKET}

\section{A. Kondisi Eksisting Rumah Apung}

Kondisi penggunaan rumah apung di Indonesia terbilang masih belum pernah diaplikasikan secara umum oleh masyarakat Indonesia, penggunaan rumah apung modern di Indonesia masih hanya sekedar riset teknologi yang dilakukan oleh pemerintah dan institusi perguruan tinggi. Beberapa kendala yang ditemukan mengapa perkembangan rumah apung di Indonesia sangatlah minim, diantaranya adalah :

a. Belum adanya Industri manufaktur khusus rumah apung

b. Indonesia tidak ada peraturan yang secara eksplisit mengatur mengenai rumah apung.

c. Market pasar yang masih terbatas

\section{B. Kondisi Pariwisata Bahari}

Menurut undang-undang No 10 Tahun 2009 tentang Kepariwisataan : "Wisata Bahari atau Tirta adalah usaha yang menyelenggarakan wisata dan olahraga air, termasuk penyediaan sarana dan prasarana serta jasa lainnya yang dikelola secara komersial di perairan laut, pantai, sungai, danau, dan waduk". Dengan 17.504 pulau, $95.181 \mathrm{~km}$ garis pantai, pantai dan laut yang indah, keanekaragaman hayati laut tertinggi di dunia, Indonesia memiliki potensi pariwisata bahari terbesar di dunia [4].

Luas ekosistem terumbu karang di Indonesia mencapai $85.707 \mathrm{~km}^{2}$ (18\% dari total luas terumbu karang di dunia), 10 ekosistem terumbu karang terindah dan terbaik di dunia, 6 berada di Indonesia meliputi Raja Ampat, Wakatobi, Taka Bone Rate, Bunaken, Karimun Jawa dan PulauWeh). Komunitas mangrove terluas di dunia, yaitu 4,25 juta ha atau
$27 \%$ dari luas hutan mangrove dunia (15,9 juta ha ) dan 236 jenis ikan hias terdapat di perairan Indonesia.

\section{Segmentasi dan Pasar Produk Rumah Apung}

Dalam perencanaan pembuatan industri rumah kayu diperlukan konsumen yang akan membeli produk dari hasil industri tersebut. Dari hasil peninjauan tentang kondisi pariwisata bahari yang ada di Indonesia Dalam kaitannya, penilaian forecasting nilai permintaan pasar pada segementasi yang sudah ditentukan sendiri menggunakan pendekatan kualitatif atau pendapat (judgement) dari penulis, dikarenakan produk rumah apung belum pernah ada data penjualan dan terbilang produk yang baru didalam pasar Indonesia, pendekatan variabel yang digunakan penulis sebagai bahan pertimbangan penilaian nilai permintaan pasar Indonesia adalah sebagai berikut :

- Kondisi pariwisata bahari indonesia

Penilaian penulis terhadap permintaan pasar rumah apung Indonesia mengacu pada kondisi pariwisata bahari Indonesia dimana kondisi sumber daya alam, popularitas pariwisata serta sarana dan pra-sarana pendukung pariwisata bahari sangat menentukan permintaan rumah apung di Indonesia.

- Pariwisata rumah apung eksisting di dunia

Variabel penialaian penulis yang selanjutnya adalah dengan membandingkan antara jumlah fasilitas rumah apung yang sudah exsisting di dunia dan lokasi pariwisata bahari setempat dengan lokasi pariwisata bahari yang ada di Indonesia dengan begitu asumsi penulis adalah dapat ditemukan nilai pendekatan pasar yang akan terjual pada kondisi pariwisata bahari di Indonesia pada kawasan wisata bahari terkait. Tabel 1 . Menjelaskan lokasi nilai potensi pasar di 15 tempat pariwisata pasar potensial dari rumah apung.

Tabel 1.

Potensi Pasar Rumah Apung di Indonesia

\begin{tabular}{|c|l|l|l|c|c|}
\hline No. & \multicolumn{1}{|c|}{ Nama Lokasi } & \multicolumn{1}{|c|}{ Kota } & \multicolumn{1}{c|}{ Provinsi } & $\begin{array}{c}\text { Jumlah } \\
\text { Wisatawan } \\
2015\end{array}$ & $\begin{array}{c}\text { Potensi } \\
\text { Pasar (Unit) }\end{array}$ \\
\hline 1 & Trio Gili & Lombok & Nusa Tenggara Barat & 62957 & 30 \\
\hline 2 & Danau Sentani & Jayapura & Papua & 31000 & 15 \\
\hline 3 & Danau Toba & Kep. Samosir & Sumatera Utara & 175463 & 25 \\
\hline 4 & Taman Laut Bunaken & Manado & Sulawasi & 84300 & 30 \\
\hline 5 & Raja Ampat & Waisai & Papua Barat & 15000 & 25 \\
\hline 6 & Danau Singkarang & Kab. Solok & Sumatera Barat & n/a & 20 \\
\hline 7 & Pulau Komodo & Sumbawa & Nusa Tenggara Timur & 40807 & 20 \\
\hline 8 & Kepulauan Seribu & Jakarta Utara & DKI Jakarta & 110000 & 20 \\
\hline 9 & Barelang & Batam & Kepulauan Riau & n/a & 5 \\
\hline 10 & Teluk Tomini & Kepulauan Togean & Sulawesi Tengah & n/a & 10 \\
\hline 11 & Kepulauan Ujung Kulon & Serang & Banten & 18000 & 20 \\
\hline 12 & Kepulauan Selayar & Takabonerate & Sulawesi Selatan & 3900 & 10 \\
\hline 13 & Kepulauan Wakatobi & & Sulawesi Tenggara & 25000 & 30 \\
\hline 14 & Telaga Ngebel & Kab. Ponorogo & Jawa Timur & 16464 & 5 \\
\hline 15 & Telaga Sarangan & Magetan & Jawa Timur & 64000 & 10 \\
\hline & & & & Total= & 275 \\
\hline
\end{tabular}




\section{ANALISIS TEKNIS INDUSTRI RUMAH APUNG}

Dalam analisis teknis dilakukan beberapa analisis pemilihan lokasi industri rumah apung, perencanaan produk, proses pembuatan produk, peralatan dan mesin yang dibutuhkan, dan layout pabrik.

\section{A. Analisis Lokasi Produk}

Penempatan Produk berada ditempat-tempat pariwisata bahari baik berupa laut, pantai dan danau yang terkenal di Indonesia. Terdapat 15 target lokasi yang diprediksi akan menjadi site utama rumah apung wisata bahari Indonesia, lokasi - lokasi tersebut dapat dilihat pada Tabel 2 Sebagai berikut :

Tabel 2

Target Lokasi Pasar Rumah Apung

\begin{tabular}{|c|l|l|l|}
\hline No. & \multicolumn{1}{|c|}{ Nama Lokasi } & \multicolumn{1}{c|}{ Kota } & \multicolumn{1}{c|}{ Provinsi } \\
\hline 1 & Trio Gili & Lombok & Nusa Tenggara Barat \\
\hline 2 & Danau Sentani & Jayapura & Papua \\
\hline 3 & Danau Toba & Kep. Samosir & Sumatera Utara \\
\hline 4 & Taman Laut Bunaken & Manado & Sulawasi \\
\hline 5 & Raja Ampat & Waisai & Papua Barat \\
\hline 6 & Danau Singkarang & Kab. Solok & Sumatera Barat \\
\hline 7 & Pulau Komodo & Sumbawa & Nusa Tenggara Timur \\
\hline 8 & Kepulauan Seribu & Jakarta Utara & DKI Jakarta \\
\hline 9 & Barelang & Batam & Kepulauan Riau \\
\hline 10 & Teluk Tomini & Kepulauan Togean & Sulawesi Tengah \\
\hline 11 & Kepulauan Ujung Kulon & Serang & Banten \\
\hline 12 & Kepulauan Selayar & Takabonerate & Sulawesi Selatan \\
\hline 13 & Kepulauan Wakatobi & & Sulawesi Tenggara \\
\hline 14 & Telaga Ngebel & Kab. Ponorogo & Jawa Timur \\
\hline 15 & Telaga Sarangan & Magetan & Jawa Timur \\
\hline
\end{tabular}

\section{B. Analisis Perencanaan Desain Produk}

Desain produk merupakan hal yang sangat penting dalam bidang manufaktur. Desain produk yang baik akan dapat meningkatkan jumlah penjualan dari produk sehingga dapat meningkatkan keuntungan secara optimal.

Perencanaan desain layout rumah merupakan salah satu proses perencanaan rumah dasar sehingga desainer dapat mengetahui gambaran tentang hasil desain yang akan dikembanggkan. Bahan material yang digunakan pada bangunan rumah utama adalah kayu meranti, dimana kayu meranti sudah memenuhi peraturan klas BKI sebagai salah satu bahan material konstruksi untuk struktur apung. Hasil perencaan desain rumah apung dapat dilihat pada Gambar 1 Gambar 4 sebagai berikut:

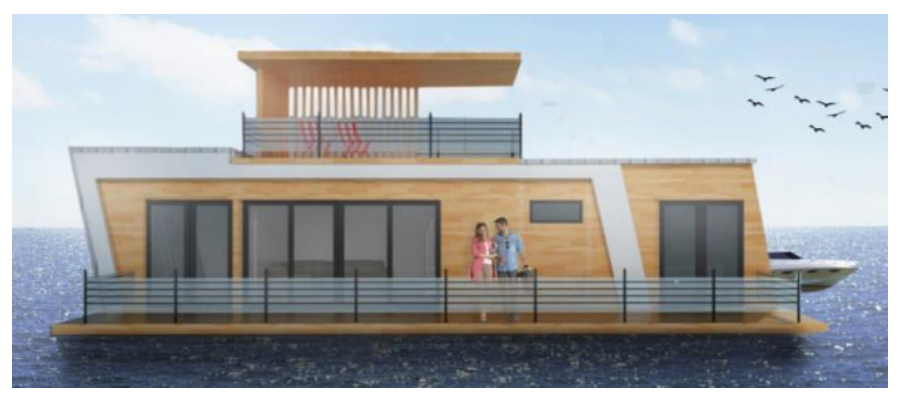

Gambar 1. Desain Rumah Apung

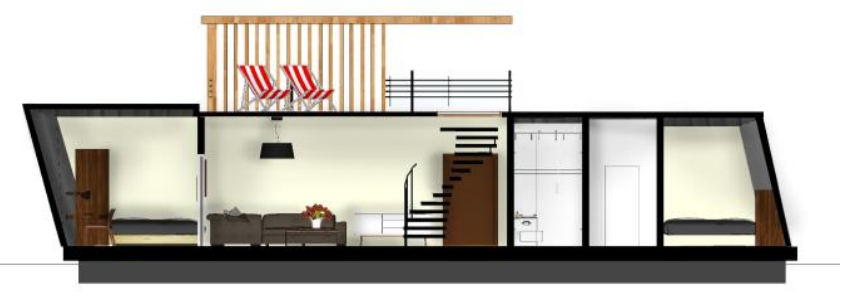

Gambar 2. Potongan Desain Rumah Apung

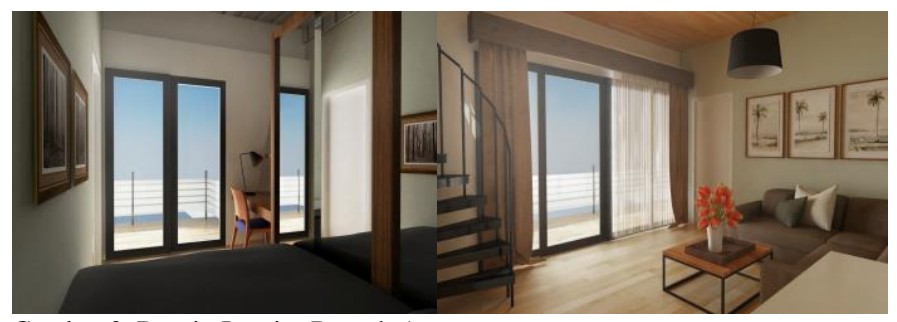

Gambar 3. Desain Interior Rumah Apung

\section{Pemilihan Material Floating Structure}

Pentingnya Pemilihan Bahan dan Proses Manufaktur merupakan salah satu keputusan yang kiritis dalam perencanaan sebuah floating structure, pemililihan material dengan melakukan penilaian terhadap material yanf dapat dilihat pada Tabel 3 yang akan menghasilkan struktur desain yang baik dalam sebuah system produksi dan operasi desain tersebut seperti, ketahanan bahan terhadap korosi (endurance), kemudahan proses produksi (fabrication) dan ekonomis pembangunan desain (economic). Dalam perencanaan material floating structure ini akan digunakan tiga buah bahan yang memungkinkan dan telah digunakan pada umumnya pada desain floating structure untuk rumah apung :

- Bahan Material Baja

- Bahan Material Aluminium

- Bahan Material EPS Foam

Tabel 3.

Penilaian Penggunaan Material Floating Structure

\begin{tabular}{|c|c|c|c|c|c|c|c|c|c|}
\hline Pertimbangan & Bobot & Sub Pertimbangan & Bobot & $\begin{array}{c}\text { Skor bahan } \\
\text { Baja }\end{array}$ & $\begin{array}{l}\text { Skor bahan } \\
\text { Alumunium }\end{array}$ & $\begin{array}{c}\text { Skor bahan } \\
\text { EPS }\end{array}$ & $\begin{array}{l}\text { Penilaian } \\
\text { Bahan Baja }\end{array}$ & \begin{tabular}{|c} 
Penilaian Bahan \\
Alumunium \\
\end{tabular} & \begin{tabular}{|l} 
Penilaian \\
Bahan EPS \\
\end{tabular} \\
\hline \multirow{3}{*}{$\begin{array}{c}\text { Endurance } \\
\text { (Ketahanan } \\
\text { material) }\end{array}$} & \multirow{3}{*}{0,549} & $\begin{array}{c}\text { Ketahanan } \\
\text { terhadap korosi }\end{array}$ & 0,223 & 2 & 3 & 3 & 0,245 & 0,367 & 0,367 \\
\hline & & $\begin{array}{c}\text { Ketahanan } \\
\text { terhadap api }\end{array}$ & 0,063 & 3 & 3 & 2 & 0,104 & 0,104 & 0,069 \\
\hline & & $\begin{array}{c}\text { Ketahanan } \\
\text { terhadap beban }\end{array}$ & 0,263 & 3 & 2 & 2 & 0,434 & 0,289 & 0,289 \\
\hline \multirow{4}{*}{$\begin{array}{l}\text { Fabrication } \\
\text { (Kemudahan } \\
\text { Produksi) }\end{array}$} & \multirow{4}{*}{0,120} & $\begin{array}{c}\begin{array}{c}\text { Ketersediaan } \\
\text { material }\end{array} \\
\end{array}$ & 0,053 & 3 & 2 & 1 & 0,019 & 0,013 & 0,006 \\
\hline & & $\begin{array}{c}\text { Kemudahan Prose } \\
\text { Produksi }\end{array}$ & 0,013 & 3 & 3 & 1 & 0,005 & 0,005 & 0,002 \\
\hline & & \begin{tabular}{|c} 
Kemudahan Prose \\
Perbaikan \\
\end{tabular} & 0,023 & 3 & 3 & 1 & 0,008 & 0,008 & 0,003 \\
\hline & & $\begin{array}{c}\text { Kemudahan Prose } \\
\text { Instalasi }\end{array}$ & 0,03 & 2 & 2 & 3 & 0,007 & 0,007 & 0,011 \\
\hline \multirow{3}{*}{\begin{tabular}{|l} 
Economic (Biaya \\
struktur apung)
\end{tabular}} & \multirow{2}{*}{0,331} & Biaya Produksi & 0,082 & 2 & 2 & 1 & 0,055 & 0,055 & 0,027 \\
\hline & & Biaya Perawatan & 0,249 & 2 & 1 & 3 & 0,165 & 0,082 & 0,247 \\
\hline & 1 & & 1 & 23 & 21 & 17 & 1,041 & 0,930 & 1,022 \\
\hline
\end{tabular}

\section{Desain Floating Structure}

Perencanaan desain floating stucture salah satu proses perencanaan rumah dasar terhadap kebutuhan desain layout rumah yang sudah dibuat pada perencanaan desain floating stucture ini menggunakan bahan material baja sesuai dengan hasil pembobotan nilai pemilihan material floating structure 
,berikut merupakan perencanaan desain floating stucture sebagai salah satu desain produk rumah apung. Hasil perencanaan desain floating structure dapat dilihat pada Gambar 4 sebagai berikut :
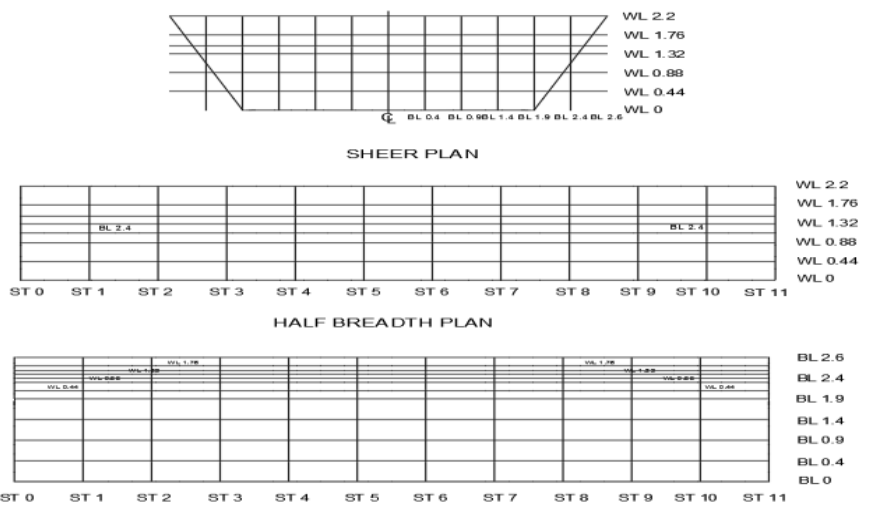

Gambar 4. Linesplan Floating Structure

Main Dimension

Length on Waterline (Lwl) : $\quad 10,000 \mathrm{~m}$

Lpp

Breadth (B)

: $10,00 \mathrm{~m}$

Depth $(\mathrm{H})$

: $5,80 \mathrm{~m}$

Draught (T)

: $2,20 \mathrm{~m}$

$\rho$

Coefficient Block $(\mathrm{Cb})$

: $1,500 \mathrm{~m}$

: 1,025 ton $/ \mathrm{m} 3$

Prismatic Coefficient $(\mathrm{Cp}) \quad$ : 0,811

Midship Coefficient $(\mathrm{Cm}) \quad: \quad 0,830$

$\mathrm{Cw}$

: 0,651

\section{E. Analisis Lokasi Pabik}

Fasilitas produksi adalah sesuatu yang dibangun, diadakan atau diinvestasikan guna melaksanakan aktifitas produksi. Selanjutnya lokasi pabrik dimaksudkan sebagai lokasi dimana fasilitas-fasilitas produksi tersebut diletakan. Lokasi pabrik (plant location) harus dibedakan dengan tata letak pabrik (plant layout). Dalam penelitian ini terdapat dua buah opsi lokasi pabrik yang sesuai dengan kondisi terkait :

- Jalan Raya Manyar, Manyar, Kab. Gresik, Jawa Timur

- Jl. Elraim Lengkong, Wangurer, Girian, Kota Bitung, Sulawesi Utara

Tabel 4.

Penilaian Lokasi Pabrik

\begin{tabular}{|c|c|c|c|c|c|c|c|}
\hline Pertimbangan & Bobot & Sub Pertimbangan & Bobot & $\begin{array}{c}\text { Skor } \\
\text { Lokasi } 1\end{array}$ & $\begin{array}{c}\text { Skor } \\
\text { Lokasi } 2\end{array}$ & $\begin{array}{c}\text { Penilaian } \\
\text { Lokasi } 1 \\
\end{array}$ & $\begin{array}{c}\text { Penilaian } \\
\text { Lokasi } 2 \\
\end{array}$ \\
\hline \multirow{2}{*}{ Kondisi Lahan } & \multirow{2}{*}{0,157} & Kemampuan Lahan & 0,079 & 3 & 3 & $\begin{array}{l}0,037 \\
\end{array}$ & 0,037 \\
\hline & & Penggunaan Lahan & 0,079 & 3 & 3 & 0,037 & 0,037 \\
\hline \begin{tabular}{|c}
$\begin{array}{c}\text { ketersediaan tenaga } \\
\text { kerja }\end{array}$ \\
\end{tabular} & 0,066 & $\begin{array}{c}\text { ketersediaan tenaga } \\
\text { kerja }\end{array}$ & 0,066 & 3 & 2 & 0,013 & 0,021 \\
\hline \multirow{3}{*}{$\begin{array}{c}\text { ketersediaan bahan } \\
\text { baku }\end{array}$} & \multirow{3}{*}{0,169} & kuantitas bahan baku & 0,056 & 3 & 1 & 0,028 & 0,009 \\
\hline & & $\begin{array}{c}\text { kontinuitas bahan } \\
\text { baku }\end{array}$ & 0,056 & 3 & 2 & 0,028 & 0,019 \\
\hline & & \begin{tabular}{|l|} 
jarak bahan baku \\
\end{tabular} & 0,056 & 2 & 1 & 0,019 & 0,009 \\
\hline Pemasaran & 0,161 & $\begin{array}{c}\text { adanya wisata bahari } \\
\text { dan psaing }\end{array}$ & 0,161 & 3 & 3 & 0,078 & 0,078 \\
\hline rencana tata ruang & 0,014 & $\begin{array}{c}\text { rencana tata ruang } \\
\text { terkait }\end{array}$ & 0,014 & 3 & 3 & 0,001 & 0,001 \\
\hline \multirow[b]{2}{*}{ modal } & \multirow[b]{2}{*}{0,2891} & \begin{tabular}{|c|} 
harga tanah per $\mathrm{m}$ \\
\end{tabular} & 0,144 & 3 & 2 & 0,125 & 0,083 \\
\hline & & $\begin{array}{c}\text { harga upah minimum } \\
\text { daerah }\end{array}$ & 0,144 & 1 & 3 & 0,042 & 0,125 \\
\hline \multirow{3}{*}{$\begin{array}{l}\text { kecukupan } \\
\text { infrastruktur } \\
\text { pendukung }\end{array}$} & \multirow{3}{*}{0,143} & kecukupan listrik & 0,071 & 3 & 3 & 0,030 & 0,030 \\
\hline & & $\begin{array}{l}\text { kecukupan jaringan } \\
\text { jalan }\end{array}$ & 0,071 & 3 & 3 & 0,030 & 0,030 \\
\hline & & kecukupan air & 0,071 & 3 & 3 & 0,030 & 0,030 \\
\hline Total & 1 & & 1 & 36 & 32 & 0,524 & 0,511 \\
\hline
\end{tabular}

\section{ANALISIS EKONOMIS}

Analisis ekonomi adalah proses pemeriksaan statistik dan indikator pasar untuk menentukan kemungkinan rencana untuk alokasi sumber daya. Analisis dapat diarahkan untuk mengembangkan rencana ekonomi tertentu atau kebijakan sebuah indstri, atau dapat digunakan untuk benar-benar memahami status ekonomi. Dalam rangka untuk melakukan analisis ekonomi dasar, adalah penting untuk memahami hubungan antara sumber daya dan kebutuhan.

\section{A. Kelayakan Investasi}

Perhitungan kelayakan investasi dilakukan berdasarkan biaya investasi, biaya produksi, biaya operasional, tax, dan pendapatan. Dengan biaya investasi awal sebesar Rp 5.895.716.000 yang dibebankan $30 \%$ dari modal pribadi sebesar Rp 1.768.714.000 dan 70\% merupakan pinjaman dari bank sebesar Rp 4.127.000.000. dengan pendapatan per tahun dilihat pada Tabel 5. Langkah pertama yang dilakukan adalah menghitung laba (rugi) dari industri rumah apung.

Tabel 5.

Cash Flow Industri Rumah Apung

\begin{tabular}{|c|c|c|c|c|c|c|c|}
\hline \multirow{3}{*}{ DESKRPPSI } & & \multicolumn{6}{|c|}{ TAHUN } \\
\hline & & 2017 & 2018 & 2019 & 2020 & 2025 & 2026 \\
\hline & & 0 & 1 & 2 & 3 & 8 & 9 \\
\hline \multicolumn{8}{|l|}{ Dana Awal } \\
\hline Modal Sendiri & & 1.714 .716 .000 & & & & & \\
\hline Pinjaman & & 4.001 .000 .000 & & & & & \\
\hline & & & & & & & \\
\hline \multicolumn{8}{|l|}{ Investasi } \\
\hline Investasi Infrasturktur & & 4.490 .5000 .000 & & & & & \\
\hline Investasi Peralatan dan Mesin & & 1.225 .216 .000 & & & & & \\
\hline Total & & 57.715 .716 .000 & & & & & \\
\hline \multicolumn{8}{|l|}{\begin{tabular}{|l|} 
Jang Masuk \\
\end{tabular}} \\
\hline Pendapatan & & & 3.600 .000 .000 & 3.600 .000 .000 & 4.800 .000 .000 & 7.200 .000 .000 & 7800.000 .000 \\
\hline Target Penijualan (@600.0000.000) & & & 6 & 6 & 8 & 12 & 13 \\
\hline \multicolumn{8}{|l|}{ Uang Keluar } \\
\hline Biaya langsung & & & $(2.597 .100 .600)$ & $(2.597 .100 .600)$ & $(2.846 .100 .600)$ & $(4.577 .501 .000)$ & $(4.702 .001 .000)$ \\
\hline Biaya Tidak langsung & & & $(708.000 .000)$ & $(708.000 .000)$ & $(708.000 .000)$ & $(708.000 .000)$ & $(708.000 .000)$ \\
\hline \multicolumn{8}{|l|}{ Uang Keluar Berdasarkkan Aktivitas Keuangan } \\
\hline Pembayaran Angsuran Pinjaman & & & $(123.452 .600)$ & $(136.106 .558)$ & $(150.057 .480)$ & $(244,427,823)$ & $(269.481 .675)$ \\
\hline Pembayaran Angsuran Bunga Pinjaman & & & $(410,102.623)$ & $(397.448 .725)$ & (383.497.803) & $(289.127 .460)$ & $(269.481 .675)$ \\
\hline \multicolumn{8}{|l|}{ Uang Keluar Berdasarkan Aktivitas Investasi } \\
\hline Investasi Ulang & & & $(9.873 .500)$ & $(10.712 .748)$ & $(11.623 .331)$ & $(17.477 .499)$ & (18.963.087) \\
\hline Total Pengeluaran & & & (3.848.529.383) & $(3.849 .368 .631)$ & $(4.099 .279 .214)$ & $(5.836 .533 .783)$ & $(5.967 .927 .436)$ \\
\hline Pendapatan Sebelum Pajak & & & $(248.529 .383)$ & (249.368.631) & 700.720 .786 & 1.363.466.217 & 1.832 .072 .564 \\
\hline Pajak & $10 \%$ & & 24.852 .938 & 24.936 .863 & $(70.072 .079)$ & $(136.346 .622)$ & $(183.207 .256)$ \\
\hline Pendapatan Setelah Pajak & & & $(223.676 .445)$ & $(224.431 .768)$ & 630.648 .707 & 1.227 .119 .596 & 1.648 .865 .307 \\
\hline Akumulasi Pendapatan & & & $(223.676 .445)$ & (448.108.212) & 182.540 .495 & 5.638.088.078 & 7.286 .953 .385 \\
\hline Return of Invesment & & & $(5.939 .392 .445)$ & $(6.163 .824 .212)$ & $(5.533 .175 .505)$ & $|(77.627 .922)|$ & 1.571 .237 .385 \\
\hline
\end{tabular}

Tabel 6.

Nilai Payback Period, NPV dan IRR

\begin{tabular}{|r|c|r|r|}
\hline ROI & $:$ & 1.571 .237 .385 & rupiah \\
\hline NPV & $:$ & 1.071 .681 .793 & rupiah \\
\hline IRR & $:$ & $12,32 \%$ & \\
\hline \multirow{3}{*}{ Payback Periode } & \multirow{2}{*}{$:$} & 9,05 & tahun \\
\cline { 3 - 4 } & & 9,0 & tahun \\
\cline { 3 - 4 } & & $\mathbf{0 , 5 6}$ & bulan \\
\hline Kelayakan & $:$ & Go Project/ Layak & \\
\hline
\end{tabular}

Berdasarkan Tabel 6 didapatkan bahwa Payback Periode untuk pengembangan industri rumah apung pada tahun ke-9 dengan nilai ROI sebesar $\mathrm{Rp}$ 1.571.237.385 Kemudian dilakukan pembulatan ke atas, sehingga didapatkan nilai Pay Back Periode kira-kira sebesar Rp 1.571.240.000, Net Present Value untuk pengembangan industri rumah apung sebesar Rp 1.071.682.793 Kemudian dilakukan pembulatan ke atas, 
sehingga didapatkan nilai Net Present Value kira-kira sebesar Rp 1.071.682.000. Internal Rate of Return adalah 12,32\%. Nilai IRR sebesar $12,32 \%$, lebih besar dari bunga bank yang telah ditetapkan yakni $10,25 \%$. Sehingga investasi ini layak dilakukan di Indonesia dikarenakan potensi pasar yang luas dan jumlah kompetitor industri rumah apung yang masih sedikit.

\section{KESIMPULAN}

Setelah dilakukan penelitian maka kesimpulan dari Studi ini adalah sebagai berikut:

1. Hasil perencanaan desain rumah apung didapatkan adalah sebagai berikut:

- Spesifikasi desain bangunan rumah dalam perencanaan desain dengan bahan material utama kayu jati adalah :

$\begin{array}{llll}\text { Gross Area } & : 66,3 \quad \mathrm{~m} 2 \\ \text { Net Area } & : 37,2 \mathrm{~m} 2 \\ \text { Front Terrace } & : 23,85 \mathrm{~m} 2 \\ \text { Back Terrace } & : 5,25 \quad \mathrm{~m} 2 \\ \text { 2nd Floor } & : 16,22 \mathrm{~m} 2 \\ \text { Weight of Structure } & : 16,22 \text { Ton } \\ \text { Total Weight (full load) } & : 18,02 \text { Ton }\end{array}$

- Ukuran utama dari floating structure ini dengan bahan material utama baja adalah :

Length on Waterline (Lwl) : $10,00 \mathrm{~m}$

Lpp $\quad: 10,00 \mathrm{~m}$

Breadth (B) : $5,8 \quad \mathrm{~m}$

Depth $(\mathrm{H}) \quad: 2,20 \mathrm{~m}$

Draught $(\mathrm{T}) \quad: 1,5 \quad \mathrm{~m}$
2. Analisis teknis yang dihasilkan untuk pengembangan industri rumah apung adalah sebagai berikut:

- Pemilihan lokasi untuk pengembangan industri rumah apung terletak di Jalan Raya Manyar, Manyar, Kab. Gresik, Jawa Timur. Luas tanah $1200 \mathrm{~m} 2$ dan kapasitas produksi sebanyak 16 unit rumah apung per-tahun.

- Proses proses produksi rumah apung terbagi menjadi 2 proses yang berbeda yaitu, proses produksi rumah dan proses produksi floating structure:

- Proses produksi struktur rumah meliputi fabrikasi dan forming, painting, Assembly, dan commissioning

- Proses produksi floating structure meliputi fabrikasi dan sub-assembly, painting, Assembly, dan commissioning.

3. Biaya investasi yang diperlukan dalam pengembangan industri rumah apung $\mathrm{Rp}$ 5.715.716.000. Payback Period terjadi pada tahun ke 9 dengan nilai sebesar $\mathrm{Rp}$ 1.571.240.000. Nilai Net Present Value kira-kira sebesar Rp 1.071.682.000, Nilai Internal Rate of Return sebesar $12,32 \%$ lebih besar dari bunga pinjaman bank yang ditetapkan sebesar $10,25 \%$.

\section{DAFTAR PUSTAKA}

H. Frick, Arsitektur Ekologis. Konsep arsitektur ekologis di iklim tropis, penghijauan kota dan kota ekologis, serta energi terbarukan. Yogyakarta: Kanisius, 2006.

[2] E. Watanabe, Hydroelastic analysis of pontoon-type VLFS. 2004.

[3] M. Nazir, Metode Penelitian. Jakarta: Ghalia Indonesia, 1998.

[4] A. G. . dan R. Stenee, IndoPacific Coral Reef Field Guide. Singapore: Tropical Reef Research Publ, 2002. 